\title{
Review of ISCoS textbook on comprehensive management of spinal cord injuries
}

Havinder Singh Chhabra (Editor-in-Chief)

ISCoS Textbook on Comprehensive Management of Spinal Cord Injuries ISBN-13: 978-93-5129-440-5

\section{Spinal Cord (2015) 53, 899; doi:10.1038/sc.2015.191}

Dr Havinder Singh Chhabra, his co-editors, support staff, along with 186 authors and co-authors have combined to create a masterful text that will serve as the most universal and authoritative reference for all aspects of the topic of spinal cord injury (SCI) for years to come by beginners and experienced professionals alike.

The text contains 1250 pages (a number that Leo Tolstoy, if he were alive today, would no doubt applaud) and is unique in that it not only contains information that is state of the art in developed countries, but also information as to how the best care can be provided in developing regions with limited resources.

The format of all 82 chapters is ideal for the learner. Each chapter contains not only learning objectives to orient the student to the content that follows, a summary of points to remember after each section and a list of key (take away) points at the end of the chapter followed by an exhaustive bibliography. The learner will also appreciate the list of abbreviations with their explanations at the front and the glossary and index at the back, all of which are easily accessible.

The images, figures, diagrams and tables are of excellent quality. In this regard, although all chapters are excellent resources of information, some deserve special mention: chapters 8-24 on fracture management, 29 on neurogenic bladder, 34-36 on therapy and orthotics, 37 on the tetraplegic hand, 38 on assistive technology, 42 on the consumer's perspective, 48 on the integumentary system, 49 on musculoskeletal complications, 57 on discharge planning, 63 on issues unique to pediatric SCI and 73-80 on prevention of SCI.

As with many comprehensive works that set out to cover so much ground, especially a topic so complex as SCI, some things may be inadvertently omitted. For example, in chapter 1 (history) no reference is made to the interesting polemics between Sir Charles Bell and Sir
Astley Cooper over conservative vs surgical treatment of SCI in the 19th century. Also, it is surprising that John Young, MD was not included among the founding fathers. He was the driving force behind the formation of the US SCI Model Systems and the American Spinal Injury Association (ASIA). In chapter 2 (pathophisiology) the fine works of Professor Byron Kakulas who provided extensive specimens of post mortem SCI is not mentioned. In chapter 29 (neurogenic bladder) the advantages of a catheter team as a means of maintaining quality control and cross infection control as advocated by Guttmann, Bedbrook and many others is not discussed. In chapter 57 (predischarge planning) a well written chapter, especially the paragraphs dealing with equipment prescription, it would have been nice if the vexing problem in some countries of third party payers setting limits on length of stay based on cost not care had been mentioned. In chapter 69 (rights) although excellent, the controversial 'right' of patients to decide, based on the recognized ethical principle of autonomy, to end their own lives would have provided an interesting dimension, given that suicide is reported by the US SCI Model Systems as the 8th or 10th (depending on how the data are analyzed) most common cause of death among persons with SCI. Finally, in chapter 71 (translational research) only passing reference is made to ethical considerations. Lessons learned from the past, procurement of human stem cells and the ensuring of research integrity by scientists, institutions and industry would have been welcome if space allowed.

The citing of the above omissions is intended not to subtract from the overall excellence of the text but merely to alert readers and authors of suggestions that might add to subsequent editions.

Dr Chhabra and his team have accomplished everything they set out to do. As a result, this book will serve as an excellent companion to elearnSCI.org as well as every SCI specialist's library.

WH Donovan Department of Physical Medicine \& Rehabilitation UT Houston, Emeritus Vice President of Medical Affairs, The Institute for Rehabilitation and Research, Houston, TX 77030, USA E-mail: William.Donovan@memorialhermann.org 